\section{A fenomenologia existencial e a perspectiva histórica no personalismo de Emmanuel Mounier}

Adão José Peixoto

Professor da Faculdade de Educação -

Universidade federal de Goiás - UFG

Resumo: Este texto procura apresentar a fenomenologia existencial praticada pelo pensamento personalista de Emannuel Mounier no seu esforço de elaboração de uma antropologia da pessoa que, inserida na história real, responde a um apelo de transcendência. Por isso, Mounier foi um pensador mais preocupado com a significação da existência humana, do ser pessoal, do que com a tecnicidade do processo epistêmico. Essa exigência epistemológica significa, no personalismo, a tentativa de elaboração de uma fenomenologia da existência, em que a pessoa é referência. A existência humana é o ponto de partida e o postulado fundamental do personalismo. A pessoa não é entendida pelo personalismo como uma realidade desvinculada do mundo, mas como uma realidade historicamente encarnada. A condição de ser "situado", isto é, encarnado no seu tempo, na sua história, intervindo nela e transformando-a continuamente, é a forma pela qual o homem se realiza como pessoa, pois o que fundamentalmente o caracteriza como tal é a sua capacidade de romper os determinismos e afirmar a sua personalidade.

Palavras-chave: personalismo.,fenomenologia, história.

\author{
Existential phenomenology and historical \\ perspective on the personalism of \\ Emmanuel Mounier
}

\begin{abstract}
This paper seeks to present the existential phenomenology practiced by the Emmanuel Mounier personalist thinking in his effort of elaborating a person anthropology that, inserted on the true history, responds to a transcendent appeal. Hence, Mounier was a thinker more concerned with the meaning of human existence, of the personal being, than with the technicality of the epistemic process. This epistemological requirement means, in personalism, the attempt to elaborate a phenomenology of existence, in which the person is reference. Human existence is the starting point and the fundamental postulate of personalism. The person is not understood by personalism as a reality disconnected of the world, but as a historically embodied reality. The condition of being "set", ie, embodied in its time, in its history, intervening in it and transforming it continuously, is the way man is realized as a person, because what fundamentally characterizes him is his ability to rupture the determinism and assert his personality.
\end{abstract}

Keywords: personalism, phenomenology, history 


\section{Introdução}

É possível perceber no Personalismo de Mounier uma orientação baseada na fenomenologia existencial e na abordagem histórica. A questão da metodologia não aparece explicitamente no pensamento desse filósofo. Não aparece, por dois motivos. Primeiro porque uma de suas principais críticas era contra o formalismo do rigor lógico que, na obra de muitos pensadores, se sobrepõe à preocupação com o humano, tornando-se um sistema, uma abordagem tecnicamente rigorosa, mas vazia de sentido humano. Segundo porque, sendo a pessoa o objeto de investigação do seu pensamento, é de natureza diferente e, como tal, necessita de uma orientação teórico-metodológica também diferenciada.

Por isso, o personalismo faz implicitamente uma reformulação epistemológica. Essa exigência de ruptura com os modelos lógicos da filosofia de inspiração racionalista, em que o rigor tem um fim em si mesmo, apresenta, nas entrelinhas das obras de Mounier, uma tentativa de se estabelecer uma nova lógica para a abordagem do ser pessoal. Segundo Severino (1983: 129),

[...] esta reformulação da epistemologia é exigida pela condição especial do objeto de reflexão filosófica: a pessoa bumana. Sendo esta simultaneamente imanente $e$ transcendente no seu modo de ser, ela se constitui, até certo ponto, como mistério, pouco transparente aos olhares da razão. A condição existencial da pessoa desnorteia, pois não oferece ao filósofo uma totalidade sistematizável no nivel da evidência lógica.

Sendo a pessoa uma realidade não objetável e, portanto, não redutível a um esquema teórico rígido, é necessário compreendê-la com base em uma concepção de razão que não seja restrita à concepção de herança racionalista, como se a razão fosse a única fonte do conhecimento verdadeiro, favorecendo, dessa forma, o estabelecimento de uma dicotomia entre razão e mundo, sujeito e objeto. É preciso uma razão alargada [raison élarge], como já propôs Merleau-Ponty, considerando-se como conhecimento válido não só o da perspectiva da lógica do pensamento iluminista, mas também as outras manifestações da existência humana, não captadas por uma orientação racionalista e/ou empirista. Para esse filósofo, "a tarefa é, pois, alargar nossa razão para torná-la capaz de compreender aquilo que em nós e nos outros precede e excede a razão" (MERLEAU-PONTY, 1989: 151).

O que Merleau-Ponty propõe é a superação da razão instrumental ou despersonalizada que nega a dimensão do simbólico, do imaginário, da subjetividade. Diferentemente do que imagina a concepção positivista, o simbólico, o imaginário e as outras formas de manifestação da subjetividade não são puras abstrações, mas são também uma dimensão do real, uma dimensão que dá vida e sentido à

Revista de Filosofia Moderna e Contemporânea

Brasília, vol 3, no 2, 2015. 
razão humana, tornando-a fonte de esperança.

O real não é só o empírico, os elementos do mundo dos sentidos, o que pode ser previsto. Se o real fosse só o previsto, saberíamos de antemão as respostas para tudo. Estaríamos circunscritos ao mundo do previsível, não teríamos o novo, e sim apenas a repetição.

A concepção do conhecimento como processo lógico-técnico estabelece uma dicotomia entre objetividade e subjetividade. $\mathrm{O}$ que se entende por objetividade, por exemplo, na filosofia racionalista, uma das vertentes do pensamento iluminista, é o que é demonstrável pela razão. É por essa razão que o a priori cartesiano entendia por razão a razão matemática e a física: "[...] a objetividade é o correlato da razão e esta é garantida na ciência como elaboração críticoreflexiva das realizações da razão" (LUIJPEN, 1973: 169). A objetividade, assim, fica reduzida a uma elaboração lógica.

O empirismo, outra vertente do iluminismo, entende que o conhecimento válido é somente o conhecimento capaz de ser empiricamente demonstrável. A racionalidade está, portanto, na objetividade do conhecimento.

Para o positivismo, também outra vertente do iluminismo, o conhecimento válido é o conhecimento objetivo, neutro e empiricamente comprovável.

Mounier critica tais posturas epistemológicas. De acordo com ele, a razão não pode ser reduzida a esses rigores lógicos e técnicos. A razão é muito mais do que isso, pois é também a expressão das múltiplas manifestações da existência humana, na maioria das vezes não exprimíveis em categorias de quantidade. O que Mounier propõe, implicitamente, é a concepção da razão numa perspectiva existencial. O filosofar, para ele, ganha sentido no diálogo e no confronto com a existência e com a história.

\section{A Orientação fenomenológico existencial}

Severino (1983: 129), ao abordar o diálogo e confronto do personalismo com a existência, afirma que,

[...] partindo-se da concepscão da filosofia como uma atitude dialógica da consciência bumana com o real, bem se vê que a própria realidade não se deixa mais revelar através das expectativas epistemológicas tradicionais da filosofia. O dialogar é uma revelação vivencial, é uma atitude mais complexa e mais rica do que uma simples representação lógica.

A pessoa, em sua totalidade, é inacessível a uma abordagem positivista e racionalista. O conhecimento da pessoa não pode "se isolar do exercício vivo e integral da experiência humana, toda ela feita de contingência, de fragilidade, de plenitude e não só de perspicácia e clarividência" (SEVERINO, 1983: 130). Assumir essa postura não é cair num irracionalismo, mas situar a "razão dentro dos limites de uma experiência, cujo conteúdo nada tem de claro e distinto" (SEVERINO, 1983: 130).

A busca da reformulação epistemológica por parte do personalismo é uma tentativa de elaboração de uma fenomenologia da existência, "situada entre o objetivismo radical da ciência e o subjetivismo da metafísica" (SEVERINO, 1983: 131). Para Mounier, o personalismo não pode fundar-se numa psicologia cientificista,

Revista de Filosofia Moderna e Contemporânea

Brasília, vol 3, no 2, 2015. 
A fenomenologia existencial e a perspectiva histórica no personalismo de Emmanuel Mounier

centrada numa orientação analítica e objetivista. A primeira orientação transforma o espírito num instrumento manipulável, que se compõe e decompõe. A segunda orientação impede o afloramento da subjetividade naquilo que ela tem de específico ( $c f$. SEVERINO, 1983: 131). Também não pode comprometerse com a metafísica encerrada num subjetivismo fascinado pelos encantos "das ideias puras". Afastando-se da história e da experiência concreta da vida pessoal, "a metafísica estratificou-se nos seus próprios instrumentos lógicos, esquecendose da opacidade do ser, sobretudo do ser do homem" (SEVERINO, 1983: 131). A abordagem do ser pessoal exige mais do que o estabelecimento de relações objetivas e/ ou lógicas. Do ponto de vista epistemológico,

[...] este projeto personalista de uma nova e mais rica compreensão do ser da pessoa, que não seja aquela estruturação objetivante da psicologia e das demais ciências humanas, ou aquela elucidação puramente lógica da metafísica essencialista, significa a delimitação de uma fenomenologia existencial. (SEVERINO, 1983:131)

A fenomenologia surgiu como uma tentativa de superação da dicotomia entre sujeito e objeto, entre o homem e o mundo que foi introduzida pelo racionalismo e pelo empirismo. O racionalismo, como já se viu, afirma que conhecimento verdadeiro é aquele que advém do sujeito. $\mathrm{O}$ empirismo advoga que o conhecimento válido é o que surge do objeto. Para a fenomenologia, essa dicotomização é equivocada. A experiência intencional nos mostra que esses dois polos são indissociáveis, formam uma unidade dialética.
Para a fenomenologia, toda consciência é "consciência de", o que afirma o caráter de "intencionalidade" da relação homemmundo. $\mathrm{O}$ mundo aqui não é entendido como o somatório das "coisas" existentes nem dos objetos produzidos pelo homem. O mundo, na perspectiva da fenomenologia,

\section{[...] apresenta um sentido que transparece na interseção das experiências tanto individuais como coletivas, e na inter- relação que se estabelece entre os diversos lugares desta mesma experiência. Isto, no entanto, não quer dizer que o mundo seja simplesmente o seu sentido. É este sentido encarnado na existência. (REZENDE, 1990: 40)}

O mundo de que fala a fenomenologia é o mundo humano, é o mundo da cultura, produto das relações homem-homem, homem-natureza. Não há uma razão metahistórica que define a existência do mundo. Essa existência é determinada pela trama existencial dos homens. Existe uma relação eminentemente dialética entre o homem e o contexto natural e cultural. Para Rezende (1990: 35-36), na concepção fenomenológica,

[...] homem não é o mundo, o mundo não é o homem, mas um não se concebe sem 0 outro. É neste sentido fundamental que a dialética se faz.presente no seio mesmo da estrutura fenomenal [...] o que faz. a função existencial das duas é a intencionalidade, isto é, a experiência fundamental de um ser aberto-ao-mundo.

Por conseguinte, a fenomenologia provocou uma profunda revisão, tanto da concepção do sujeito (consciência) quanto do objeto (mundo). Consciência e subjetividade não são percebidas apenas

Revista de Filosofia Moderna e Contemporânea

Brasília, vol 3, no 2, 2015. 
como inteligência, espírito, liberdade, nem só como corporeidade, determinismo, inconsciente, mas em constante relação dialético-existencial. Por sua vez, o mundo não é visto só como matéria, produto, instituição, condicionamento, mas mundo humano, marcado pela presença do homem "ao mundo e no mundo" ( $c f$. REZENDE, 1990: 36).

Outra concepção que a fenomenologia tenta superar é a que reduz as explicações do homem, da sociedade, da educação etc. apenas aos fatores econômicos. MerleauPonty (1971: 14), pensando em Marx, escreve:

\section{[...] é verdade, como disse Marx, que a bistória não caminha sobre a cabeça, mas é verdade igualmente que ela não pensa com os pés. Melhor dizendo, não temos que nos ocupar nem com sua cabeça nem com seus pés, mas com seu corpo.}

Isso significa que, para a fenomenologia, o mundo não deve ser visto apenas a partir do econômico, da política, da ideologia, da luta de classes, "mas de todas as maneiras pelas quais temos acesso ao sentido", conforme afirma Rezende (1990: 40).

Posso dizer que a fenomenologia apareceu como uma tentativa de superação dos impasses epistemológicos surgidos da concepção dualista que opõe "ser" e "conhecer". Esse empreendimento que se atingiu, inicialmente, acabou, segundo Severino (1983: 131), "dando vantagem ao dualismo que tanto criticara". A fenomenologia, especialmente a vertente husserliana, assumiu uma orientação excessivamente lógica. Mesmo assim, "sua perspectiva é válida e prenhe de promessa, explicando-se assim seu fecundo aproveitamento nas filosofias das existências, entre as quais se insere o próprio Personalismo" (SEVERINO, 1983: 131).

É da perspectiva fenomenológico-existencial que o personalismo se vale para se fundamentar metodologicamente. Mounier não se preocupou em afirmar essa aproximação entre o personalismo e a fenomenologia existencial. Contudo, essa aproximação está presente em toda a obra de Mounier e fez surgir o método fenomenológicopersonalista, voltado para o ser pessoal, ser este entendido como um mistério, pois nunca é captado inteiramente. $O$ ser pessoal é, para o personalismo, um absoluto, uma referência de todas as iniciativas.

As críticas que a fenomenologia teceu às concepções filosóficas que dicotomizaram o processo do conhecimento e às concepções filosóficas economicistas e à sua tentativa de superá-las por meio da afirmação da existência fizeram com que o personalismo se aproximasse dessa orientação teóricometodológica. Por isso, o Personalismo parte dessa orientação teóricometodológica, mas vai além, ao procurar dar-lhe um sentido mais existencial, um sentido que traduz o ser da pessoa, da "existência situada".

\section{A Orientação Histórica}

Outra orientação teórico-metodológica adotada pelo personalismo, inclusive admitida pelo próprio Mounier, é a abordagem histórica, que está imbricada nessa orientação fenomenológicoexistencial que acabamos de apresentar. Toda obra de Mounier está inserida numa situação histórica. A pessoa de que fala o personalismo é um ser historicamente

Revista de Filosofia Moderna e Contemporânea

Brasília, vol 3, no 2, 2015. 
A fenomenologia existencial e a perspectiva histórica no personalismo de Emmanuel Mounier

situado. É um ser que se realiza como homem na história. Por isso, é sempre um ser envolto com o apelo da reflexão e do engajamento para que sua ação se torne efetivamente práxis. Segundo Lorenzon (1996: 17), o personalismo "edificou-se pouco a pouco através de um método de reflexão e ação em ligação estreita com o homem concreto e os problemas humanos da história".

Para o personalismo, pensar a existência é pensar a própria condição do homem como ser encarnado na história, ser que, ao se fazer ser pessoal, faz história, história pessoal e coletiva.

Dizer que para o personalismo o ser pessoal é um ser histórico significa que é um ser de ação, um ser que dá significação à sua existência. $\mathrm{O}$ destino humano não é algo dado, pronto, mas continuamente construído na relação que o homem mantém com os outros homens, com o mundo do trabalho e com o mundo cultural. Isso significa que os acontecimentos como obra humana têm uma finalidade, têm um sentido. Para Candide Moix (1968: 349), "dizer que há uma história não significa somente que coisas se passam, ou que memórias retêm fatos. E afirmar que o conjunto dos acontecimentos que concerne ao homem e ao universo tem um sentido: uma direção e uma significação".

O próprio Mounier admitia que a orientação metodológica por ele adotada era a abordagem histórica. Ele afirma:

Dissemos suficientemente que nosso método não consiste em aplicar à realidade principios imóveis, mas em depreender as revelações da História à luz de uma direção de pensamento que permanece ao mesmo tempo constante e viva, quando se alimenta sempre da lição dos fatos. (Apud MOIX, 1968: 39)

O fazer humano, a ação humana construindo história, só se constitui em progresso quando é instrumento de humanização, quando é "progresso para o homem, isto é, para toda a humanidade" (MOIX, 1968: 354). Para Mounier, "um progresso indefinido, do qual todos os homens da História não conhecem os frutos, seria para inúmeras gerações o triunfo da noite e da injustiça” (Apud MOIX, 1968: 354).

Entretanto, Mounier não percebe o desenvolvimento técnico-científico como uma marcha irrefreável para a catástrofe, pois é obra humana e, como tal, o homem faz dela aquilo que quer. Mesmo assim, Mounier tem clareza de sua complexidade. Por isso afirma que o homem "deve, antes de tudo, desmistificar os problemas, e exorcizar as idiotices do medo. Os problemas da máquina nos ofuscam, mas não são os mais terríveis" (Apud MOIX, 1968: 360).

Contra o "catastrofismo", que só vê na história, na trajetória humana, apenas o horror, e contra o otimismo "irrefletido", o otimismo ingênuo que acredita que os rumos da história vão mudar apenas pela intervenção de uma entidade sobrenatural ou pela intervenção de um sindicato, de um partido ou de uma pessoa, Mounier propõe o "otimismo trágico", a percepção das duras contradições da sociedade (trágico), mas também a percepção de que tais contradições são obras humanas que podem ser transformadas pelos próprios

Revista de Filosofia Moderna e Contemporânea

Brasília, vol 3, no 2, 2015. 
homens (otimismo). Essas mudanças devem ocorrer simultaneamente em cada um de nós e nas estruturas sociais. Tratase, portanto, de mudanças integrais.

O mundo de que fala Mounier é um mundo que tem uma história, que está a cada instante sendo construída individual e coletivamente. É uma história que tem um sentido, tem uma intencionalidade individual e coletiva. Para Mounier, o sentido da história

\section{[...] está assinalado de uma obscura vocação para a grandeza bumana e sobre- humana, mas através de uma história dramática feita de irrupções e de quedas, de iluminacões e de solidões, cuja unidade ainda desconhecida só se elabora pelo dilaceramento e pela luta. (Apud MOIX, 1968: 368)}

O sentido de angústia diante dos dramas e a percepção da condição de autor e obra desta situação colocam nas mãos dos homens o próprio destino da história. É por isso que a visão de Mounier sobre a história é de um "otimismo trágico". Para ele, "entre o otimismo impaciente da ilusão liberal ou revolucionária e o pessimismo impaciente dos fascismos, o caminho próprio do homem é esse otimismo trágico em que ele encontra sua justa medida num clima de grandeza e de luta" (Apud MOIX, 1968: 369).

O método fenomenológico-existencial e a abordagem histórica na perspectiva personalista procuram ser fiéis à experiência existencial do homem (pessoa) como ser absoluto que deve ser o referencial de toda organização social, colocando a pessoa como horizonte de todo horizonte.
Mesmo que a preocupação seja com o homem (pessoa), este não é compreendido como um ser individualista, fechado no seu mundo egocêntrico, mas como "permanência aberta" (MOUNIER, 1964: 111), existência voltada para os outros e para o mundo.

\section{O que é o personalismo}

A Europa e várias outras partes do mundo foram vítimas, a partir de 1929, de uma profunda crise política, moral e social provocada, inicialmente, por outra crise, a crise econômica, em conseqüência da queda da bolsa de Nova York, e posteriormente pela ascensão do nazismo, do fascismo e pela Segunda Guerra Mundial. Nesse contexto, o que predominava eram o pessimismo, a banalização, a negação da pessoa e a falta de perspectivas.

O marxismo e o espiritualismo se apresentavam como a salvação dessa crise (cf. CHAIGNE, 1969). Os marxistas afirmavam que tal crise era uma decorrência da crise econômica; era uma "crise de estrutura", crise de enfraquecimento do modo de produção capitalista. A saída seria mudar as estruturas econômicas, abolir a propriedade privada e instituir o comunismo. Portanto, "operem a economia, o doente se recuperará". Para os espiritualistas, a crise é uma "crise de valores", é uma crise não da economia, mas do homem. "Mudem os homens, e as sociedades se curam" (CHAIGNE, 1969: 59).

Mounier se coloca contra essas saídas, por entender que elas são parciais, reducionistas, não apreendem a complexidade da crise. Trata-se de crise que não é uma consequência só da crise econômica, como diziam os

Revista de Filosofia Moderna e Contemporânea

Brasília, vol 3, no 2, 2015. 
A fenomenologia existencial e a perspectiva histórica no personalismo de Emmanuel Mounier

marxistas, ou só da crise de valores, como diziam os espiritualistas, mas de ambas. Como saída, deve ser ao mesmo tempo uma mudança das estruturas econômicas e dos valores.

Escreve Mounier (1990: 199):

Não estávamos satisfeitos com nenbum deles. Parecia-nos que espiritualistas e marxistas participavam do mesmo erro. Erro que consistia em separar o corpo e a alma, o pensamento e a ação, o homo faber $e$ o homo sapiens. Afirmávamos, por outro lado: a crise era ao mesmo tempo econômica e espiritual, crise de estruturas, crise do homem. Não retomávamos somente a palavra de Péguy: "A revolução será moral ou não será revolução". Afirmávamos: "A revolução moral será econômica, ou não será revolução. A revolução econômica será moral ou não será nada". (Tradução nossa)

Como forma de superar a dicotomia estabelecida pelo marxismo e o espiritualismo, Mounier lança, em 1932, na França, o movimento personalista, tendo como principal veículo de divulgação de suas ideias a revista Esprit.

O personalismo é uma filosofia que afirma o valor da pessoa como valor absoluto (MOUNIER, 1964). O absoluto aqui é entendido como fim que dá sentido a toda organização política e social. Quando Mounier (1990: 209-210) se refere à pessoa como absoluto, quis dizer, segundo o próprio autor:

$1 .^{\circ}$ - que uma pessoa não pode jamais ser considerada como meio por uma coletividade ou por outra pessoa; que não existe espirito impessoal, acontecimento impessoal, valor ou destino impessoal; o impessoal é a matéria; 2. ${ }^{\circ}$ - que, em conseqüência, excluidas as circunstâncias excepcionais em que o mal não pode ser detido se não à força, é condenável qualquer regime que, de direito ou de fato, considere as pessoas como objetos intercambiáveis, as dirija on as constranja contra a vocação do homem [...]; $3 .^{\circ}$ - que a sociedade, isto é, o regime legal, jurídico, social e econômico não tem por missão nem subordinar a si pessoas, nem assumir a realização de sua vocação [...] $4^{\circ}$ - É a pessoa que far sen destino: outra pessoa, nem homem, nem coletividade pode substitui-la. (Tradução nossa)

Partindo dessas considerações, podemos dizer que o intuito do personalismo é a construção da pessoa como totalidade e como centro de todas as ações. O nosso dia a dia histórico deve se constituir numa afirmação radical do caráter inalienável, insubstituível e, portanto, absoluto da pessoa.

Ao afirmar o valor absoluto da pessoa, Mounier não está propondo a edição de um novo individualismo, pois o que ele mais combateu foi justamente o individualismo da civilização burguesa.

Para o personalismo, tomar o ser humano como pessoa é apreendê-lo como ser que se constrói historicamente, como ser situado, ser de comunicação, de adesão, de transformação. Isso mostra que o personalismo, ao apostar no ser humano, está também apostando na comunidade,

[...] já que a pessoa é comunicação essencial, é sair de si, é compreender, assumir o seu próprio destino e o destino das outras pessoas. A responsabilidade e a

Revista de Filosofia Moderna e Contemporânea

Brasília, vol 3, no 2, 2015. 
fidelidade são os eixos que estruturam a idéia da comunidade como "persona de personas". (MOSQUERA, 1990: 33)

Ao mesmo tempo em que afirmou o valor absoluto da pessoa, Mounier anunciou também a importância da vida comunitária. O homem, segundo Mounier, só se torna pessoa e se realiza como tal em comunidade. É por isso que, na perspectiva personalista, o social e o político são expressões do pessoal. É por isso que Mounier clama a favor de uma revolução ao mesmo tempo personalista e comunitária. Quer, com isso, uma revalorização da vida das pessoas e da vivência comunitária. Para garantir essa reestruturação, é necessária uma profunda transformação política e social, de modo que todas as instituições sejam estruturadas em função da promoção da pessoa.

O termo personalismo não é novo. Ele foi inicialmente empregado por Renouvier ( $c f$. MOUNIER, 1964) em 1903, para nomear o seu pensamento. Mas foi com Mounier que ganhou radicalidade e a dimensão de uma filosofia. Para Mounier (1990: 181, tradução nossa), esse termo (personalismo) "responde ao desabrochar da força totalitária, nasceu dela, contra ela; acentua a defesa da pessoa contra a opressão das estruturas". Mounier entende que, sob esse ângulo, o personalismo corre o risco de reacender velhas manifestações individualistas. Para evitar isso é que ele teve a preocupação de associar a dimensão pessoal à dimensão comunitária.

\section{Conclusão}

Atualmente também vivemos uma profunda crise de valores que tem deixado graves consequências. O processo de "globalização" que toma conta do mundo está instaurando uma relativização dos valores humanos. Nesse contexto, a existência humana, como ocorreu na Segunda Guerra Mundial, pouco importa. A preocupação fundamental é com a acumulação do capital. Por isso, os principais valores da sociedade são cada vez mais o consumismo, o individualismo e a concorrência. Esses são os valores básicos da era da "qualidade total", da "eficiência" e da pretensa "neutralidade". Anunciam o fim das ideologias e a vitória do capitalismo. Este último é anunciado como razão suprema da história, como supremacia da "razão instrumental" sobre a "razão crítica", segundo Habermas (1983), ou da razão "personalizada", segundo Mounier. Esta é a era da impessoalidade, o lugar por excelência do indivíduo e não da pessoa, como já denunciava Mounier. Daí a importância de se recolocar o personalismo no centro dos debates. $O$ personalismo ainda continua sendo uma referência fundamental para se pensar em novas perspectivas de superação desse modelo de negação da pessoa e da vida comunitária.

A escola é uma das instituições mais atingidas por essa crise. A ideologia da homogeneização da sociedade global tenta apagar as diferenças, a criatividade e as resistências. Tenta, enfim, substituir a utopia pelo desencanto e pelo conformismo.

Revista de Filosofia Moderna e Contemporânea

Brasília, vol 3, no 2, 2015. 


\section{Referências bibliográficas}

BENJAMIN, Walter; HORKHEIMER, Max; ADORNO, Theodor W.; HABERMAS, Jürgen. Textos escolbidos. Traduções de José Lino Grünnewald et al. 2. ed. São Paulo: Abril Cultural (Coleção Os Pensadores).

CHA I GNE, Hervé. "Que é o personalismo". In: DOMENACH, JeanMarie et al. (Org.). Presença de Mounier. Tradução de Maria Lúcia Moreira. São Paulo: Duas Cidades, 1969.

LORENZON, Alino. Atualidade do personalismo de Emmnuel Mounier. Ijuí: Ed. Unijuí, 1996.

LUIJPEN, William. Introdução à fenomenologia existencial. Tradução de Carlos Lopes de Matos. São Paulo: EPU; Ed. Universidade de São Paulo, 1973.

MERLEAU-PONTY, Maurice. Fenomenologia da percepção. São Paulo: Freitas Bastos, 1971.

MERLEAU-PONTY, Maurice. Textos escolbidos. Tradução de Marilena de Souza Chaui e Pedro de Souza Moraes. São Paulo: Nova Cultural, 1989. (Coleção Os Pensadores).

MOIX, Candide. O pensamento de Emamuel Mounier. Tradução de Frei Marcelo L. Simões. Rio de Janeiro: Paz e Terra, 1968.

MOUNIER, Emmanuel. O personalismo. Tradução de João Bérnard da Costa. São Paulo: Duas Cidades, 1964.

MOUNIER, Emmanuel. Obras completas. Traducción de Antonio Ruiz et al.

Revista de Filosofia Moderna e Contemporânea

Brasília, vol 3, no 2, 2015.
Salamanca, España: Ed. Sígmeme, 1990. Tomo III.

MOUNIER, Emmanuel. Obras completas. Traducción de Antonio Ruiz et al. Salamanca, España: Ed. Sígmeme, 1992. Tomo I.

MOSQUERA, Juan Mouriño. "A atualidade pedagógica e relevância humana na obra de Mounier". Revista Filosófica Brasileira, Rio de Janeiro: UFRJ, Depto. de Filosofia, v. V, n. 1, p. 31-39, dez. 1990.

REZENDE, Antonio Muniz de. Concepsão fenomenológica da educação. São Paulo: Cortez/Autores Associados, 1990.

SEVERINO, Antonio Joaquim. Pessoa e existência: iniciação ao personalismo de Emmanuel Mounier. São Paulo: Cortez/ Autores Associados, 1983. 